\title{
Analysis of bio-markers serum levels in IVIG and infliximab refractory Kawasaki Disease patients
}

Running title: Infliximab therapy for Kawasaki disease

Keywords

Kawasaki disease; infliximab; granulocyte-colony-stimulating factor; interferon-gamma inducible protein 10; soluble tumor necrosis factor-alpha receptor

Authors:

Akira Hachiya $^{1}$, Norimoto Kobayashi ${ }^{1}$, Satoshi Matsuzaki ${ }^{1}$, Yusuke Takeuchi ${ }^{1}$, Yohei Akazawa ${ }^{1}$, Tomonari Shigemura ${ }^{1}$, Noriko Motoki ${ }^{1}$, Junya Masumoto ${ }^{2}$, Kazunaga Agematsu ${ }^{1,3}$

1. Department of Pediatrics, Shinshu University School of Medicine, Matsumoto, Japan

2. Department of Pathology, Ehime University Proteo-Science Center and Graduate School of Medicine, Ehime, Japan

3. Department of Infection and Host Defense, Graduate School of Medicine, Shinshu University Matsumoto, Japan

Address correspondence to: Kazunaga Agematsu, Department of Infection and Host Defense, Graduate School of Medicine, Shinshu University Asahi 3-1-1, Matsumoto 390-8621, Japan. Phone: +81-263-37-3228; Fax: +81-263-37-3092;

E-mail: nagematsu@nifty.com 


\begin{abstract}
Introduction: Infliximab (IFX) is effective for treatment of refractory Kawasaki disease (KD). However, the precise mechanisms and biomarkers for IFX efficacy are unknown. We tried to evaluate the effect and response to IFX therapy by measuring serum cytokine levels.

Methods: Twenty-nine children with KD who had been resistant to 2 courses of high-dose intravenous immunoglobulin were enrolled and treated with IFX. Plasma samples were analyzed for cytokines before and after IFX administration.

Results: Serum levels of interleukin-6, granulocyte-colony-stimulating factor (G-CSF), interferon-gamma-induced monokine, interferon-gamma inducible protein 10 (IP-10), monocyte chemotactic protein 1, and soluble tumor necrosis factor-alpha receptor (sTNFR) 1 and 2 were significantly elevated before IFX treatment, but promptly decreased after the administration. The pre-treatment G-CSF and sTNFR1 levels in non-responders to IFX were significantly higher than in responders, who were defined as patients who defervesce $\left(<37.5^{\circ} \mathrm{C}\right)$. After IFX administration, elevated cytokines declined to normal ranges in responders, but in nonresponsive group, G-CSF and sTNFR1 remained elevated without failing to normal levels. Conclusions: IFX treatment significantly reduced the levels of serum cytokines, chemokines, and sTNFRs in refractory KD. G-CSF and sTNFR1 may be indicators predictive of poor response to IFX.
\end{abstract}




\section{INTRODUCTION}

Kawasaki disease (KD) is an acute systemic inflammatory vasculitis in infants and young children [1], preferentially affecting the coronary arteries that is the leading cause of acquired heart disease. The therapeutic methods for KD have progressed drastically over the last half century. High-dose intravenous immunoglobulin (IVIG) is effective in suppressing inflammation and reducing the prevalence of coronary artery abnormalities when administered in the early stages of KD [2]. However, $15-20 \%$ of affected individuals do not respond to the initial IVIG treatment and harbor greater risk of coronary artery aneurysm formation [3, 4]. Recently, anti-tumor necrosis factor (TNF)- $\alpha$ therapy has emerged as a rescue treatment for patients with refractory KD. As anti-TNF- $\alpha$ monoclonal antibody, infliximab (IFX) has been reported as safe and effective for reducing fever duration [5-10]. Nevertheless, the precise mechanisms and prognostic biomarkers for IFX therapy in KD remain poorly understood.

Previous studies have suggested KD to be an immune-mediated disease in which cytokines might be responsible for disease development and progression. Several investigations have identified elevated serum levels of multiple pro-inflammatory cytokines, such as TNF- $\alpha$, interleukin (IL)-1 $\beta$, IL-6, IL-8, IL-18 and interferon (IFN)- $\gamma$, in acute phase KD [11-13]. Increased expression of monocyte chemotactic protein (MCP)-1 has also been observed in $\mathrm{KD}$, whose expression declines after IVIG [14]. High levels of soluble tumor necrosis factor-alpha receptor (sTNFR) 1 were detected in the serum during acute stage of $\mathrm{KD}$, and a positive correlation was seen for TNF- $\alpha$ and sTNFR [15]. Lastly, granulocyte colony-stimulating factor (G-CSF) is elevated in most of KD patients, and elevated G-CSF can predict IVIG treatment failure in $\mathrm{KD}[16]$.

Ko et al. most recently identified serum interferon-gamma inducible protein-10 (IP-10) to be specifically increased in KD in comparison with other febrile diseases and thereby excellent biomarker for differentiating KD cases [17]. IP-10 is secreted by several cells, including T lymphocytes, neutrophils, monocytes, and endothelial cells, under the influence of multiple cytokines, such as IFN- $\gamma$, IFN- $\alpha$, and TNF- $\alpha$, depending on the cell type $[18,19]$. IP-10 promotes the migration of activated Th1 lymphocytes [20] and functions, not only as a chemotactic factor, but also as a potent inhibitor of angiogenesis [21].

In the present study, we investigated the cytokine profiles of patients with IVIG-resistant KD before and after IFX therapy to identify biomarkers that could estimate the effect of IFX among responders, and non-responders. 


\section{PATIENTS AND METHODS}

\subsection{Ethical Statement}

This investigation on IFX therapy for refractory KD and its analysis of cytokine profiles for KD were approved by the institutional review board of Shinshu University (No. 993 and 2781). Written informed consent was obtained from legal guardians.

\subsection{Patients}

We enrolled 29 children (12 girls and 17 boys; mean age: 37 months) with $2^{\text {nd }}$ IVIG resistant KD transferred to Shinshu University Hospital from July 2007 through April 2015. All subject were of Japanese ethnicity and fulfilled the criteria outlined by Diagnostic Guidelines for Kawasaki Disease ( $5^{\text {th }}$ revision) published by the Kawasaki Disease Research Committee in Japan [22], with the exception of 1 case of incomplete type of KD. The patients had received initial treatments at institutions other than our hospital of $2.0 \mathrm{~g} / \mathrm{kg}$ IVIG for 1-2 days twice, alone with either $30 \mathrm{mg} / \mathrm{kg} /$ day oral aspirin or $3-5 \mathrm{mg} / \mathrm{kg} /$ day flurbiprofen due to the liver dysfunction at the onset of KD. Refractory KD to IVIG was defined as axillary temperature of over $37.5^{\circ} \mathrm{C}$ persisting more than 24 hours after the $2^{\text {nd }} I V I G$.

IFX treatment was begun within 8 days of disease onset in all patients. Intravenous $5 \mathrm{mg} / \mathrm{kg}$ IFX in $100 \mathrm{ml}$ saline over 2 hours was administered in an open-label manner. No anaphylactic reactions were observed. Patients were re-assessed 24 hours after IFX infusion. Clinical data, including age, sex, duration of illness, and the results of routine laboratory tests, such as white blood cell (WBC) count, neutrophil count, C-reactive protein (CRP), aspartate aminotransferase (AST), alanine aminotransferase (ALT), and lactate dehydrogenase (LDH), were obtained from medical records. Strong inflammatory activity was evident in all KD patients such as elevated WBC count and serum CRP levels before IFX administration (Table 1).

We defined patients who responded to IFX (responder group, $n=13$ ) as those who had defervesced $\left(<37.5^{\circ} \mathrm{C}\right)$ within 24 hours after the completion of IFX treatment with no subsequent recurrent fever. Those patients who exhibited persistent fever $\left(>37.5^{\circ} \mathrm{C}\right)$ lasting more than 24 hours or recrudescent fever associated with KD symptoms after a 24-hour afebrile period were placed in the non-responder group $(n=16)$. The pre-treatment clinical characteristics and laboratory data of the overall cohort and patient subgroups are summarized in Table 1. Fever lessened slightly in 12 patients in non-responder group, but remained over $37.5^{\circ} \mathrm{C}$ at 24 hours following IFX administration. No significant differences were apparent between the responder and non-responder groups regarding age at $\mathrm{KD}$ onset, principal $\mathrm{KD}$ symptoms, $\mathrm{WBC}$ 
count, neutrophil count, or serum levels of CRP, AST, ALT, or LDH before IFX infusion (Table 1). Eleven of 16 non-responders required additional therapy: 8 received additional IVIG therapy and 3 were further treated with plasma exchange therapy. In contrast, no patient needed supplemental KD treatment in responders.

\subsection{Measurement of serum cytokines}

Blood samples were collected just prior to IFX treatment and at 24-96 hours after completion. There was no significant difference in the timing of blood sample collection after IFX between the groups (median time after IFX administration; responders, 38.3 hours; nonresponders; 39.5 hours, $\mathrm{p}=0.57$ ). Collected sera were immediately frozen and stored at $-40^{\circ} \mathrm{C}$ until measurement of cytokines. Serum values of IL-1 $\beta$, IL-6, IL-8, IL-10, IL-17A, IFN- $\gamma$, TNF$\alpha$, G-CSF, IP-10, interferon gamma induced monokine (MIG), and MCP-1 were determined by BDTM Cytometric Bead Arrays (BD Biosciences, Piscataway, USA) according to the manufacturer's instructions. Data were analyzed using the BD Cytometric Bead Array software (version 3.1). sTNFR1 and sTNFR2 were quantified by ELISA (R\&D Systems, Minneapolis, USA), and IL-18 was quantified by ELISA (MBL, Nagoya, Japan) according to manufacturer's directions.

\subsection{Statistical analysis}

Group comparisons for laboratory data, and cytokine and chemokine levels were performed using the Kruskal-Wallis test. Changes in each parameter were assessed using the Friedman test. Statistical differences were considered to be significant when the $\mathrm{p}$ value upon two-tailed $\mathrm{t}$ testing was less than 0.05. All statistical analyses were performed using JMP9 statistical software (JMP Statistical Discovery, North Carolina, USA).

\section{RESULTS}

\subsection{Serum cytokine, chemokine, and sTNFR levels}

We first assessed the concentrations of serum cytokines, chemokines, and sTNFRs before IFX administration in our cohort. As reported elsewhere in KD patients at disease onset [14-16, 23-24], serum IL-6, IL-18, G-CSF, IP-10, MIG, MCP-1, and sTNFR1 and 2 were significantly elevated before IFX treatment in comparison with healthy controls (Figure 1). IFN- $\gamma$ and IL-1 $\beta$ were elevated in some patients only (Figure 1). We did not detect any marked differences in 
serum IL-8, IL-10, IL-17A, or TNF- $\alpha$ as compared with controls (Figure 1). At 24-96 hours after the completion of IFX infusion, IL-6, G-CSF, IP-10, MIG, MCP-1, sTNFR1, and sTNFR2 levels were significantly decreased (all p<0.0001) (Figure 2). In contrast, IL-18 had not decreased appreciably $(\mathrm{p}=0.66$ ) (Figure 2 ). Elevated IFN- $\gamma$ and IL- $1 \beta$ existing in the same patient decreased to healthy control levels after therapy (data not shown).

\subsection{Serum cytokines, chemokines, and sTNFRs between responders and non-responders}

We next compared the serum levels of cytokines, chemokines, and sTNFRs between responders and non-responders to IFX therapy. Serum G-CSF and sTNFR1 were significantly elevated among non-responders compared with responders before IFX administration $(p=0.002$, $\mathrm{p}=0.0129$, respectively) (Figure 3). Pre-treatment IL-6, IL-18, IP-10, MIG, MCP-1 and sTNFR2 between the two groups were not significantly different (Figure 3). At 24-96 hours after the completion of IFX infusion, serum values of IL-6, IP-10, MIG, MCP-1, and sTNFR2 in both responders and non-responders had declined to those of healthy controls (Figure 3). Interestingly, serum G-CSF and sTNFR1 in non-responders decreased greatly, but still maintained higher levels in comparison with responders ( $p=0.01, p=0.0069$, respectively) (Figure 3) and healthy controls ( $\mathrm{p}=0.0011, \mathrm{p}=0.0024$, respectively).

\section{DISCUSSION}

The present study revealed that serum IL-6, IL-18, G-CSF, MIG, MCP-1, IP-10, sTNFR1 and sTNFR2, were markedly up-regulated in KD patients who failed to respond to initial and $2^{\text {nd }}$ IVIG therapy. IFX treatment significantly reduced all the cytokine levels, apart from IL-18. Notably, G-CSF and sTNFR1 among non-responders before and after IFX therapy were significantly higher than those of responders, indicating that they may represent biomarkers predicting a poor response to IFX.

The observed elevations in serum cytokines, chemokines, and sTNFRs before IFX therapy were consistent with those of previous reports on KD patients before IVIG treatment [14-16, 23, 24]. We did not detect IL-10 or TNF- $\alpha$ in most of our cohort in our system, despite significant increases having been reported elsewhere in acute phase $\mathrm{KD}[13,24]$. In agreement with earlier studies $[9,25]$, significant reductions in serum IL- 6 and sTNFR1 by IFX in KD were noted in this series. Given that IFX suppressed all elevated recording apart from IL-18, our findings indicated that serum levels of those molecules might represent a useful tool to estimate the 
therapy efficacy of IFX in IVIG-resistant KD patients. Serum IL-18 decreases gradually in response to treatment in systemic juvenile idiopathic arthritis [26]. Thus, it may have declined in a delayed fashion after IFX administration in our cohort.

We witnessed that the serum levels of G-CSF and sTNFR1 were higher in IFX nonresponders before and after IFX infusion, but decreased significantly. Such findings were not evident other proinflammatory cytokines, including IL-6, IL-18, IP-10, MIG, MCP-1, and sTNFR2. G-CSF is an inflammatory cytokine associated with the proliferation, differentiation, and survival of progenitor cells committed to a neutrophilic lineage. Accordingly, neutrophil amounts were significantly higher in non-responders than in responders after IFX therapy (median, [range]: responders 3.7, [5.1-2.3] x $10^{3} / \mu 1$; non-responders 8.9, [10.7-7.6] x 10 $1 / \mu 1$; $\mathrm{p}=0.0056$ ). These results suggest that insufficient improvement of neutrophilic inflammation may be associated with an unresponsiveness to IFX in IVIG-resistant KD patients.

Abe et al. identified that G-CSF was a good biomarker for predicting the response to IVIG in patients with KD based on higher serum levels of G-CSF in IVIG non-responders than in responders [16]. Thus, it is possible that G-CSF may be used as a prediction marker of not only IVIG therapy, but also IFX therapy in KD patients. Meanwhile, sTNFR1 is ubiquitously expressed on human cells [27] and released into the circulation via shedding or alternative splicing in response to various stimuli, such as TNF- $\alpha$ [28]. A positive correlation between TNF- $\alpha$ and sTNFR1 has been reported in KD patients [15]. Although we could not detect serum TNF- $\alpha$ in most cases in our system of the low sensitivity, sTNFR1 may be an indicator of antiTNF- $\alpha$ therapy response.

Kobayashi and Egami scoring systems have been used to predict IVIG resistance in Japan $[29,30]$. Recently, Tang et al. identified a new scoring showing a relatively better performance than Kobayashi and Egami scoring systems in east China population [31]. Because there was no significant deference of most of the variables included in those systems before IFX administration between our IFX resistant and responded group (data not shown), we did not identify their variables as risk factors for IFX resistance. Therefore, the scores calculated by Tang, Kobayashi and Egami systems in IFX resistant group did not differ those in responded group. These results suggest that their scoring models may not have useful performance as the predictor of IFX resistance in the IVIG resistant KD patients.

$\mathrm{KD}$ is a pediatric vasculitis with coronary artery aneurysm as its main complication, and preventing the development of coronary artery aneurysm is the most important in treatment. 
Although associations between coronary artery aneurysm formations and IP-10 were not evaluated in this study, it is reported that patients with thoracic aortic aneurysms have shown significantly elevated serum IP-10 levels as compared with controls [29]. The internal luminal diameter of coronary artery was assessed using two-dimensional echocardiography following IFX therapy at 2 weeks after disease onset (data not shown). However, we could not evaluate the association between coronary artery aneurysm formation and serum cytokine levels because of a small number of patients having coronary artery dilatation.

In conclusion, IFX administration significantly reduced the elevated serum cytokines, chemokines, and sTNFRs in IVIG-resistant KD patients, indicating a strong suppression of inflammation. The cytokines, chemokines, and sTNFRs mentioned represent useful biomarkers for evaluating the efficacy of IFX therapy, while elevated G-CSF and sTNFR1 levels may indicate poor response to IFX. Further large-scale studies on IFX treatment for refractory KD and analyses of relevant biomarkers for IFX efficacy are warranted.

\section{Acknowledgments}

We thank Drs. Fumio Morohashi, Kuniaki Naganuma, Kesashi Aonuma, Akihiko Yabuhara, Takahisa Tsuno, Tetsuo Kubo, Yasushi Iwasaki, Ei Shimazaki, Takashi Shimizu, and Kenichi Koike for their invaluable contributions to the collection of patient samples.

\section{Informed consent}

Informed consent was obtained from all individual participants included in the study.

\section{Source of funding}

This work was supported by a Health Labour Sciences Research Grant entitled Translational research toward the clarification of autoinflammatory mechanisms by familial Mediterranean fever (FMF) inflammasomes based on the Mediterranean fever (MEFV) gene analysis (15ek0109033h0002).

\section{Conflict of interest}

Authors declare no conflicts of interest. 


\section{REFERENCES}

1. Kawasaki T (1967) Acute febrile mucocutaneous syndrome with lymphoid involvement with specific desquamation of the fingers and toes in children. Arerugi 16:178-222

2. Furusho K, Kamiya T, Nakano H, Kiyosawa N, Shinomiya K, Hayashidera T et al (1984) High-dose intravenous gammaglobulin for Kawasaki disease. Lancet 2: 1055-1058

3. Newburger JW, Takahashi M, Gerber MA, Gewitz MH, Tani LY, Burns JC et al (2004) Diagnosis, treatment, and long-term management of Kawasaki disease: a statement for health professionals from the Committee on Rheumatic Fever, Endocarditis and Kawasaki Disease, Council on Cardiovascular Disease in the Young, American Heart Association. Circulation 110:2747-2771

4. Wallace CA, French JW, Kahn SJ, Sherry DD (2000) Initial intravenous gammaglobulin treatment failure in Kawasaki disease. Pediatrics 105:E78

5. Sonoda K, Mori M, Hokosaki T, Yokota S (2014) Infliximab plus plasma exchange rescue therapy in Kawasaki disease. J Pediatr 164:1128-1132

6. Mori M, Imagawa T, Hara R, Kikuchi M, Hara T, Nozawa T et al (2012) Efficacy and limitation of infliximab treatment for children with Kawasaki disease intractable to intravenous immunoglobulin therapy: report of an open-label case series. J Rheumatol 39:864-867

7. Son MB, Gauvreau K, Burns JC, Corinaldesi E, Tremoulet AH, Watson VE et al (2011) Infliximab for intravenous immunoglobulin resistance in Kawasaki disease: a retrospective study. J Pediatr 158:644-649

8. Song MS, Lee SB, Sohn S, Oh JH, Yoon KL, Han JW, Kim CH (2010) Infliximab treatment for refractory kawasaki disease in korean children. Korean Circ J 40:334-338

9. Burns JC, Best BM, Mejias A, Mahony L, Fixler DE, Jafri HS et al (2008) Infliximab treatment of intravenous immunoglobulin-resistant Kawasaki disease. J Pediatr 2153:833838

10. Burns JC, Shimizu C, Gonzalez E, Kulkarni H, Patel S, Shike H et al (2005) Genetic variations in the receptor-ligand pair CCR5 and CCL3L1 are important determinants of susceptibility to Kawasaki disease. J Infect Dis 192:344-349

11. Chen SY, Wan L, Huang YC, Sheu JJ, Lan YC, Lai CH et al (2009) Interleukin-18 gene $105 \mathrm{~A} / \mathrm{C}$ genetic polymorphism is associated with the susceptibility of Kawasaki disease. J Clin Lab Anal 23:71-76

12. Kim DS (1992) Serum interleukin-6 in Kawasaki disease. Yonsei Med J 33:183-188

13. Matsubara T, Furukawa S, Yabuta K (1990) Serum levels of tumor necrosis factor, interleukin 2 receptor, and interferon-gamma in Kawasaki disease involved coronary-artery lesions. Clin Immunol Immunopathol 56:29-36

14. Asano T, Ogawa S (2000) Expression of monocyte chemoattractant protein-1 in Kawasaki disease: the anti-inflammatory effect of gamma globulin therapy. Scand J Immunol 51:98103

15. Furukawa S, Matsubara T, Umezawa Y, Okumura K, Yabuta K (1994) Serum levels of p60 soluble tumor necrosis factor receptor during acute Kawasaki disease. J Pediatr 124:721725

16. Abe J, Ebata R, Jibiki T, Yasukawa K, Saito H, Terai M (2008) Elevated granulocyte 
colony-stimulating factor levels predict treatment failure in patients with Kawasaki disease. J Allergy Clin Immunol 122:1008-1013

17. Ko TM, Kuo HC, Chang JS, Chen SP, Liu YM, Chen HW et al (2015) CXCL10/IP-10 is a biomarker and mediator for Kawasaki disease. Circ Res 116:876-883

18. Sauty A, Dziejman M, Taha RA, Iarossi AS, Neote K, Garcia-Zepeda EA et al (1999) The T cell-specific CXC chemokines IP-10, Mig, and I-TAC are expressed by activated human bronchial epithelial cells. J Immunol 162:3549-3558

19. Cassatella MA, Gasperini S, Calzetti F, Bertagnin A, Luster AD, McDonald PP (1997) Regulated production of the interferon-gamma-inducible protein-10 (IP-10) chemokine by human neutrophils. Eur J Immunol 27:111-115

20. Loetscher M, Gerber B, Loetscher P, Jones SA, Piali L, Clark-Lewis I et al (1996) Chemokine receptor specific for IP10 and mig: structure, function, and expression in activated T-lymphocytes. J Exp Med 184:963-969

21. Heller EA, Liu E, Tager AM, Yuan Q, Lin AY, Ahluwalia N et al (2006) Chemokine CXCL10 promotes atherogenesis by modulating the local balance of effector and regulatory T cells. Circulation 113:2301-2312

22. Ayusawa M, Sonobe T, Uemura S, Ogawa S, Nakamura Y, Kiyosawa N et al (2005) Kawasaki Disease Research C. Revision of diagnostic guidelines for Kawasaki disease (the 5th revised edition). Pediatr Int 47:232-234

23. Feng S, Yadav SK, Gao F, Yi Q (2015) Plasma levels of monokine induced by interferongamma/chemokine (C-X-X motif) ligand 9, thymus and activation-regulated chemokine/chemokine (C-C motif) ligand 17 in children with Kawasaki disease. BMC Pediatr 15:109

24. Wang Y, Wang W, Gong F, Fu S, Zhang Q, Hu J et al (2013) Evaluation of intravenous immunoglobulin resistance and coronary artery lesions in relation to Th1/Th2 cytokine profiles in patients with Kawasaki disease. Arthritis Rheum 65:805-814

25. Hirono K, Kemmotsu Y, Wittkowski H, Foell D, Saito K, Ibuki K et al (2009) Infliximab reduces the cytokine-mediated inflammation but does not suppress cellular infiltration of the vessel wall in refractory Kawasaki disease. Pediatr Res 65:696-701

26. Shigemura T, Yamazaki T, Hara Y, Ou JN, Stevens AM, Ochs HD et al (2011) Monitoring serum IL-18 levels is useful for treatment of a patient with systemic juvenile idiopathic arthritis complicated by macrophage activation syndrome. Pediatr Rheumatol Online J 9:15

27. Smith CA, Farrah T, Goodwin RG (1994) The TNF receptor superfamily of cellular and viral proteins: activation, costimulation, and death. Cell 76:959-962

28. Lantz M, Malik S, Slevin ML, Olsson I (1990) Infusion of tumor necrosis factor (TNF) causes an increase in circulating TNF-binding protein in humans. Cytokine 2:402-406

29. Kobayashi T, Inoue Y, Takeuchi K, Okada Y, Tamura K, Tomomasa T et al (2006) Prediction of intravenous immunoglobulin unresponsiveness in patients with Kawasaki disease. Circulation 113:2606-2612

30. Egami K, Muta H, Ishii M, Suda K, Sugahara Y, Iemura M et al (2006) Prediction of resistance to intravenous immunoglobulin treatment in patients with Kawasaki disease. $\mathrm{J}$ Pediatr 149:237-240

31. Tang Y, Yan W, Sun L, Huang J, Qian W, Ding Y et al (2016) Prediction of intravenous 
immunoglobulin resistance in Kawasaki disease in an East China population. Clin Rheumatol 35:2771-2776

32. Gallo A, Saad A, Ali R, Dardik A, Tellides G, Geirsson A (2012) Circulating interferongamma-inducible Cys-X-Cys chemokine receptor 3 ligands are elevated in humans with aortic aneurysms and Cys-X-Cys chemokine receptor 3 is necessary for aneurysm formation in mice. J Thorac Cardiovasc Surg 143:704-710 
Table 1. Clinical characteristics and laboratory data of $29 \mathrm{KD}$ patients prior to IFX administration

\begin{tabular}{|c|c|c|c|c|}
\hline & Total & Responders & Non-responders & $\begin{array}{c}\mathrm{P} \text { value } \\
\text { analysis** }\end{array}$ \\
\hline Donors(n) & 29 & 13 & 16 & \\
\hline Age(months)* & $34,12-85$ & $38.0,13-65$ & $32.5,12-85$ & \\
\hline Sex(male; female) & $17 ; 12$ & $7 ; 6$ & $10 ; 6$ & \\
\hline Diagnosis (day)* & $4,3-8$ & $4,3-8$ & $4,3-7$ & \\
\hline Infliximab infusion (day)* & $8,7-12$ & $9,7-12$ & $8,7-12$ & \\
\hline Body temperature $\left({ }^{\circ} \mathrm{C}\right) *$ & $38.8,39.5-38.5$ & $38.8,39.4-38.3$ & $39.1,39.8-38.5$ & 0.88 \\
\hline \multicolumn{5}{|l|}{$\begin{array}{l}\text { Clinical manifestations of KD } \\
\text { without fever before IFX ( } n \text { ) }\end{array}$} \\
\hline Conjunctivitis & 26 & 12 & 14 & \\
\hline Mucositis & 29 & 13 & 16 & \\
\hline Rash & 18 & 8 & 10 & \\
\hline Extremity changes & 20 & 8 & 12 & \\
\hline Lymphadenopathy & 27 & 13 & 14 & \\
\hline \multicolumn{5}{|c|}{ Additional treatment after IFX (n) } \\
\hline None $(\mathrm{n})$ & 5 & 2 & 3 & \\
\hline $3^{\text {rd }}$ IVIG (n) & 8 & 0 & 8 & \\
\hline Steroids $(\mathrm{n})$ & 0 & 0 & 0 & \\
\hline Plasma exchange (n) & 3 & 0 & 3 & \\
\hline Urinastatin (n) & 22 & 11 & 11 & \\
\hline $\operatorname{WBC}\left(\times 10^{3} / \mu \mathrm{l}\right) *$ & $13.6,15.9-12.2$ & $13.9,15.9-12.5$ & $13.2,15.9-12.1$ & 0.78 \\
\hline Neutrophils $\left(\times 10^{3} / \mu \mathrm{l}\right) *$ & $9.0,11.5-7.3$ & $8.6,11.5-6.6$ & $9.6,11.7-7.8$ & 0.57 \\
\hline $\operatorname{CRP}(\mathrm{mg} / \mathrm{dl}) *$ & $12.5,16.1-5.7$ & $10.9,13.0-4.2$ & $14.0,17.9-9.4$ & 0.10 \\
\hline PIt $\left(x 10^{4} / \mu \mathrm{l}\right) *$ & $41.7,50.0-30.6$ & $32.2,42.7-30.3$ & $46.4,52.7-32.4$ & 0.18 \\
\hline AST (IU/L) * & $31,39-26$ & $28,38-25$ & $31,41-28$ & 0.91 \\
\hline $\operatorname{ALT}(I U / L) *$ & $31,44-24$ & $24,32-23$ & $40,66-29$ & 0.86 \\
\hline LDH (IU/L) * & $258,292-210$ & $243,292-203$ & $268,295-224$ & 1.0 \\
\hline
\end{tabular}

KD, Kawasaki disease; IFX, infliximab; WBC, white blood cells; CRP C-reactive protein; Plt; platelets;

AST, aspartate aminotransferase; ALT, alanine aminotransferase; LDH, lactate dehydrogenase.

*Data are expressed as median, range. ${ }^{* *}$ derived from comparison of responders and non-responders. 
Figure 1.

Concentrations of serum cytokines, chemokines, sTNFR before IFX administration in the KD patients and healthy controls.

Serum IFN- $\gamma$, IL-17A, IL-8, IL-1 $\beta$, IL-10, TNF- $\alpha$, MCP-1, G-CSF, IP-10, MIG, IL-6, sTNFR1, sTNFR2, and IL-18 were measured in patients in KD before administration and healthy controls. Bars indicate the mean for each group. $p$ values are derived from comparisons of $\mathrm{KD}$ patients with healthy controls.
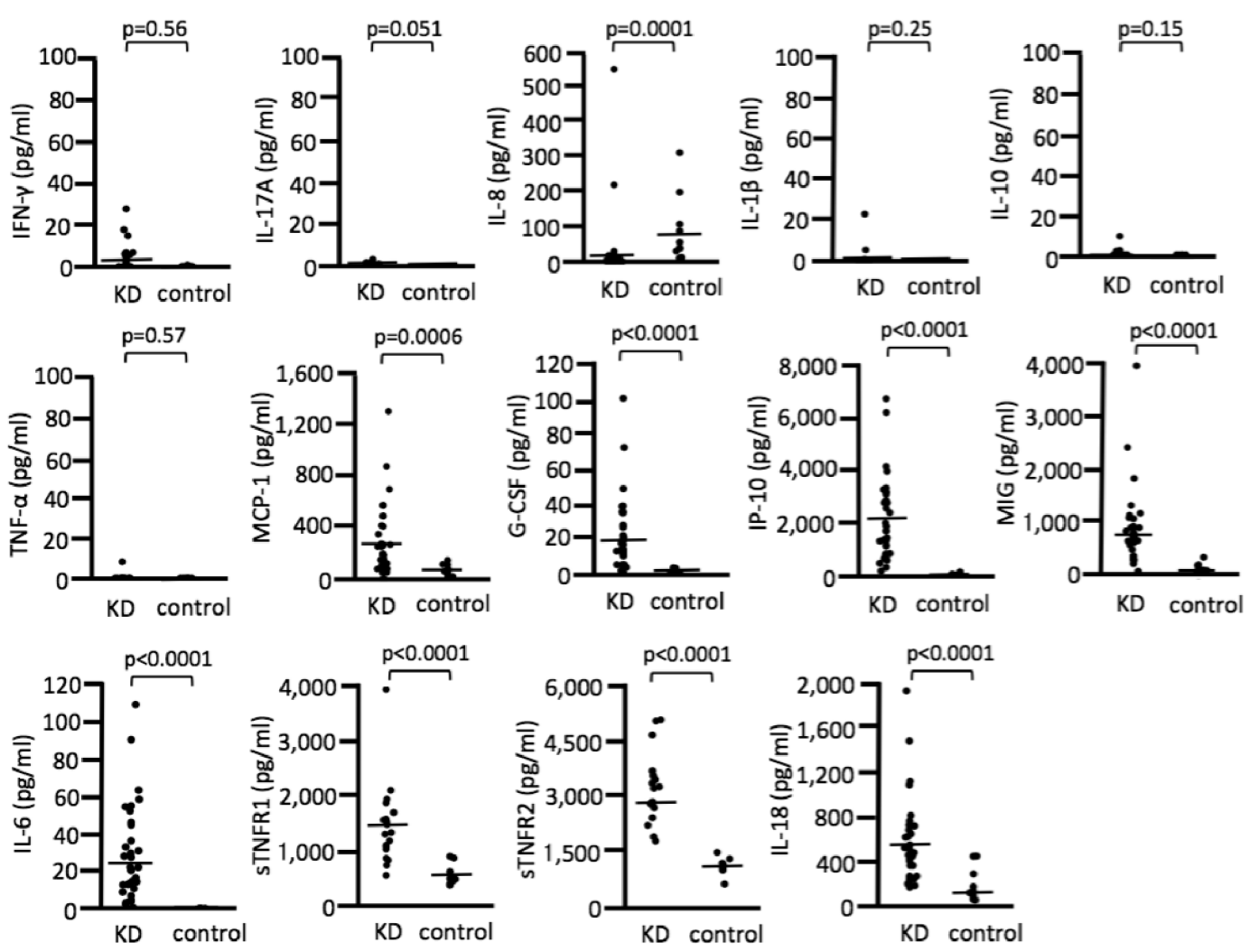
Figure 2.

Alterations in serum cytokines by IFX in KD patients.

Serum levels of IL-6, G-CSF, IP-10, MIG, sTNFR1, sTNFR2, IL-18, and MCP-1 were indicated before and after IFX therapy in KD patients. $p$ values indicate changes before and after treatment.
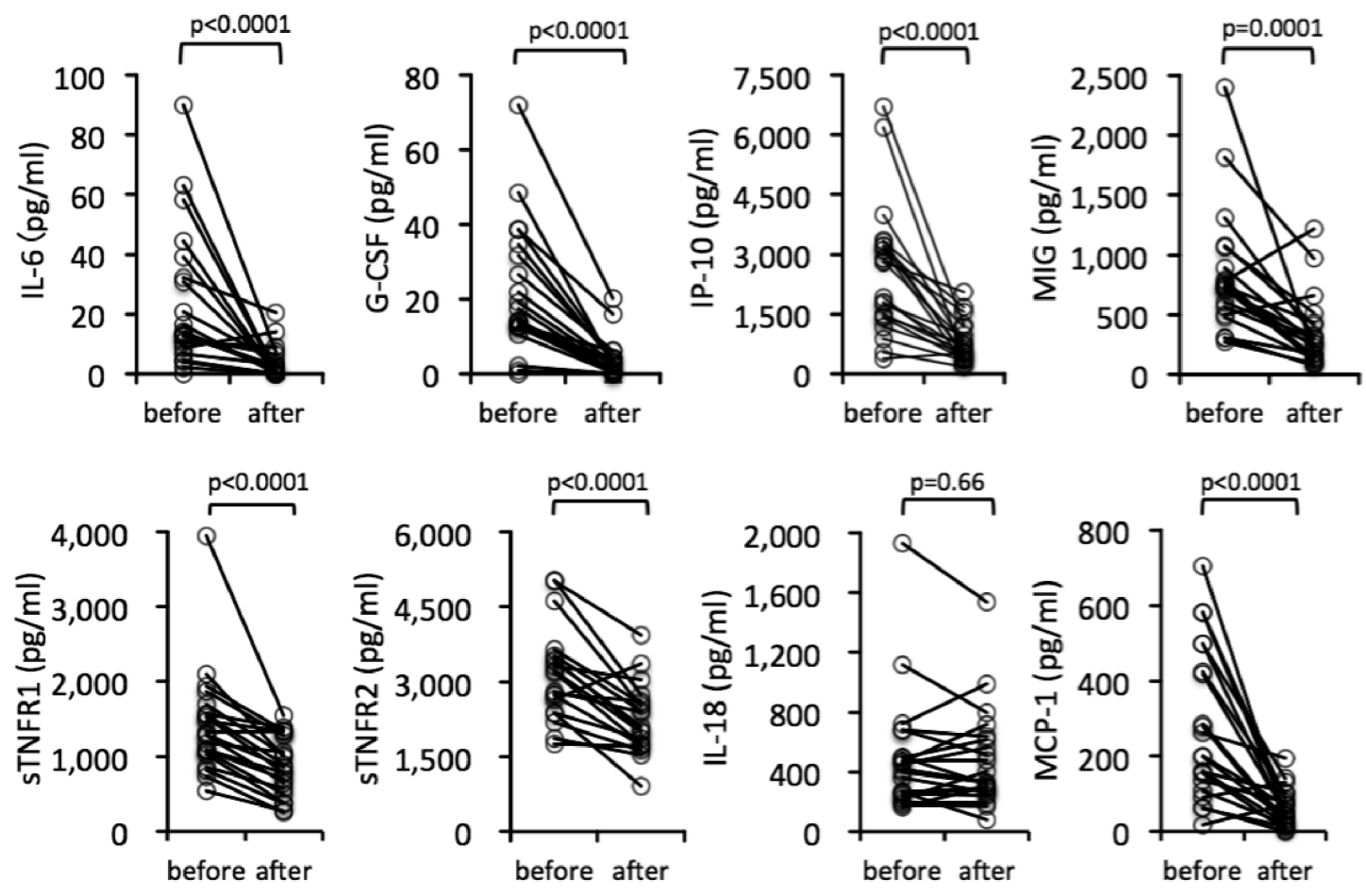
Figure 3.

Alterations in serum cytokine levels by administration of IFX in responders and nonresponders.

Serum IL-6, G-CSF, IP-10, MIG, sTNFR2, sTNFR2, IL-18, and MCP-1 were indicated in responders and non-responders before and after IFX. $\mathrm{p}$ values are derived from comparisons of responders and non-responders before and after IFX administration.

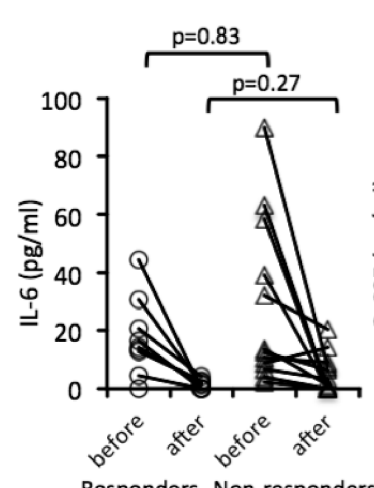

Responders Non-responders

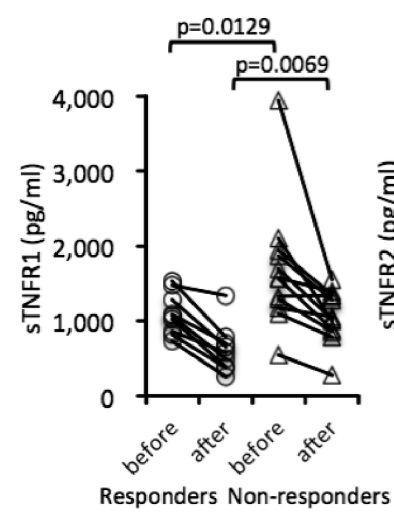

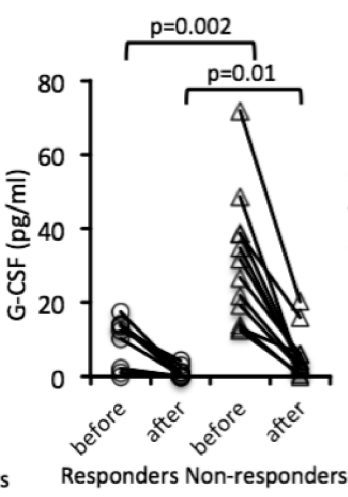

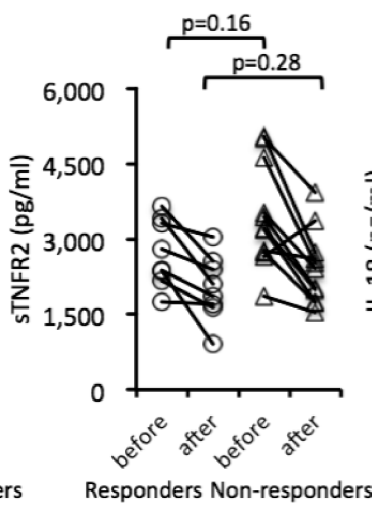

Figure 3
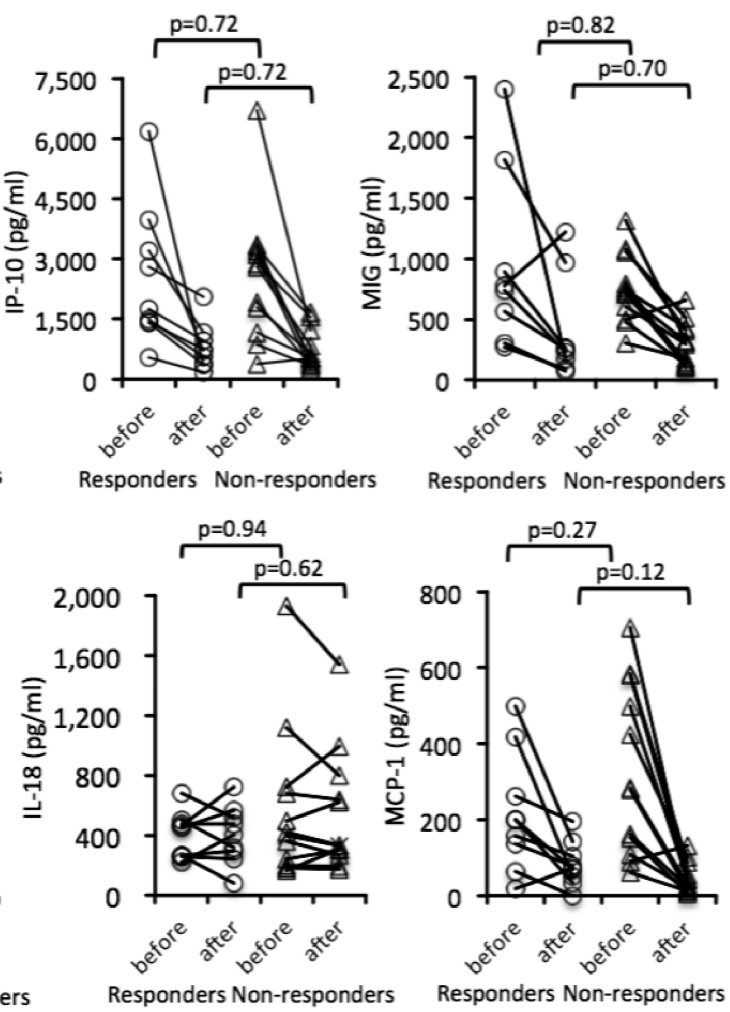